\title{
- Atualidades em tratamentos utilizados em dermatopatias de
} cães - Revisão

- Treatments for dermatopathies in dogs - A review

\section{- Actualidades en tratamientos utilizad
dermatopatías en perros - revisión}

* Anaiara Silgueiro Peixoto ${ }^{1}$

Maria Cristina de Oliveira Cardoso Coelho ${ }^{2}$ - CRMV-PE - $n^{0}$ - 1381

Margarida Bernardes Barbosa

-Rua Visc. de de Itaparica, 142 Bloco A - 103

Acadêmica em Medicina Veterinária - UFRPE

2 Prof ${ }^{a}$ Adjunta - Dep. Medicina Veterinária - UFRPE

${ }^{3}$ Acadêmica em Medicina Veterinária - UFRPE

\section{RESUMO}

As alterações dermatológicas em cães necessitam, além de um diagnóstico correto, da utilização de drogas que possuam eficácia e tragam poucos efeitos colaterais. Portanto, nesta revisão, apresentaremos informações a respeito de drogas que vêm sendo utilizadas em dermatoses parasitárias, fúngicas e bacterianas mais comuns no dia-a-dia da clínica veterinária.

Palavras-chave: Cão. Dermatose. Antifúngico. Antibacteriano. Antiparasitário. Pele.

\section{Introdução}

$\underline{\mathrm{U}}$ m dos maiores desafios para o clínico veterinário encontra-se no estabelecimento de um protocolo terapêutico adequado nos diversos casos de dermatoses existentes. Portanto, para que tenhamos um sucesso terapêutico em dermatopatias, o primeiro passo é conhecer a pele com suas estruturas em seu estado fisiológico, para que possamos então reconhecer e diagnosticar as alterações dermatológicas quando presentes. O segundo passo é o diagnóstico correto, pois sem sabermos a verdadeira causa, estaremos tratando sintomas e adiando ou, até mesmo, agravando o problema. Como último e fundamental passo, o estabelecimento de um plano terapêutico adequado. Dentre as diversas fórmulas terapêuticas que existem 
no mercado, tanto veterinário quanto humano, devemos nos ater àquelas que nos tragam uma boa resposta clínica, que seja de fácil aplicação, de baixo custo e com poucos efeitos colaterais. A escolha do fármaco também está envolvida com o agente etiológico encontrado, podendo-se utilizar, assim, drogas antibacterianas, antifúngicas, antiparasitárias e as imunossupressoras, quando o agente for a própria célula do corpo (dermatopatia autoimune). Elas podem ser indicadas para serem usadas isolada ou concomitantemente quando temos mais de um agente associado. O objetivo desta revisão é relatar sobre drogas antibacterianas, antifúngicas e antiparasitárias que são utilizadas nas dermatopatias caninas.

\section{ANTIPARASITÁRIOS}

\section{Avermectina}

As avermectinas foram desenvolvidas com as lactonas macrocíclicas produzidas pela fermentação de vários actinomicetos (SCOTT et al, 1996). A ação das avermectinas dá-se pela potencialização da liberação e dos efeitos do ácido gama-aminobutírico (GABA), tornando difícil a neurotransmissão dos estímulos nervosos para os músculos, impedindo, deste modo, a contração das células musculares. O GABA é um neurotransmissor periférico em nematóides, aracnídeos e insetos susceptíveis. Nos mamíferos, o GABA está limitado ao sistema nervoso central (SNC). (ROBERSON, 1992; NESBITT; ACKERMAN, 1998).

\section{- Ivermectina}

A ivermectina é um derivado de Avermectina B, produzida da fermentação do Streptomyces avermetilis (ROBERSON, 1992). Tendo como principal ação do medicamento a paralisia do parasita (SCOTT et al, 1996).

Sabendo-se que a ivermectina não atravessa a barreira hematencefálica, na maioria dos animais adultos, é relativamente segura e apresenta ampla margem entre a eficácia e a toxicidade para os mamíferos. A atual exceção é a raça Collie, que quase sempre parece não apresentar a barreira hematencefálica eficiente o bastante para inibir o acesso destas substâncias, quando usadas em doses mais elevadas (igual ou superior que $0,1 \mathrm{mg} / \mathrm{kg}$ ) para tratar algumas infestações por aracnídeos (ROBERSON, 1992; GRAY, 1997; NESBITT; ACKERMANY, 1998). Deste modo, seu uso nas raças Collie, Shetland Sheepdog, Old English Sheepdog, Borzoi, Border Collie, Afghan Hound, Australian Shepherd ou qual- quer cão que lembre o collie, está contra-indicado (SCOTT et al, 1996). Também deve ser evitado o seu uso em filhotes com menos de três meses de idade. A utilização concomitante com substâncias que potencializem o GABA, como o diazepam, não deve ocorrer (SCOTT et al, 1996; NESBITT; ACKERMAN, 1998).

A ivermectina possui aprovação da Administração de Alimentos e Drogas (FDA) dos Estados Unidos, para cães em dose mensal baixa de $0,006 \mathrm{mg} / \mathrm{kg}$, por via oral, na profilaxia da dirofilariose. Contudo, nem esta dose nem esta frequiência de administração são eficientes contra os ectoparasitas (ROBERSON, 1992; SCOTT et al, 1996). Embora, quando usada em doses maiores, vários artrópodes são susceptíveis ao tratamento com a ivermectina (ROBERSON, 1992; FONDATI, 1996).

Relatos experimentais indicam que doses entre $0,2 \mathrm{a}$ $0,4 \mathrm{mg} / \mathrm{kg}$ por via oral ou subcutânea, a cada duas semanas, por 2 a 3 aplicações consecutivas, são eficazes na escabiose canina (ROBERSON, 1992; MORIELLO, 1994; MORIELLO, 1995; SCOTT et al, 1996; ANDERSON, 1998; NESBITT; ACKERMAN, 1998; SCHIK; 1998; PARADIS,1999). Para a demodicose canina, a dose utilizada é entre 0,3 a $0,6 \mathrm{mg} / \mathrm{kg}$, por via oral, diariamente, quando as outras formas de tratamento não forem eficazes. $O$ tratamento deve continuar por até mais um mês após resultados negativos do exame parasitológico de pele (MORIELLO; MASON, 1995; FONDATI, 1996; MEDLEAU, 1996; SCOTT, 1996; NESBITT; ACKERMAN, 1998; CHESNEY, 1999; PARADIS, 1999; SARIDOMICHELAKIS, et al, 1999).

\section{- Selamectina}

Um novo endectocida, de uso tópico, a selamectina protege os animais de estimação contra endo e ectoparasitas. Produzida pela fermentação do Streptomyces avermetilis, é classificada como uma avermectina semi-sintética. Quando comparada com a ivermectina, ela possui um forte perfil de segurança. Dentre os variados parasitas que a selamectina atua está incluída uma eficácia comprovada contra pulgas (ovos, larvas e adultas), carrapatos, sarna sarcóptica e sarna otodécica em cães e gatos. A dose indicada é de $6 \mathrm{mg} / \mathrm{kg}$ (dose mínima), aplicada topicamente, repetindo a aplicação após 30 dias para escabiose (PRÁTICA, 2000; SHANKS, et al, 2000; SIX et al., 2000). Possui segurança para cães da raça Collie, animais lactantes e gestantes (PRÁTICA, 2000). 


\section{- Moxidectina}

A moxidectina é uma lactona macrocíclica produzida da fermentação do Streptomyces cyaneogriseus (BENSIGNOR; CARLOTTI, 1998; MATTHEW, 1999; PARADIS, 1999). Assim como toda avermectina, possui mecanismo de ação semelhante ao relatado pela ivermectina (SCOTT et al., 1996). Pode ser usada com sucesso na demodicose generalizada, com doses orais diárias de $0,4 \mathrm{mg} / \mathrm{kg}$, durante aproximadamente 5 meses, ou também a dose de $0,5 \mathrm{a} 1 \mathrm{mg} / \mathrm{kg}$, por via oral ou subcutânea, administrada 2 vezes por semana, durante aproximadamente 22 semanas (BENSIGNOR; CARLOTTI, 1998; PARADIS, 1999; DELAYTE et al., 2001; LUCAS et al., 2001).

\section{Outras Drogas Utilizadas}

- Amitraz

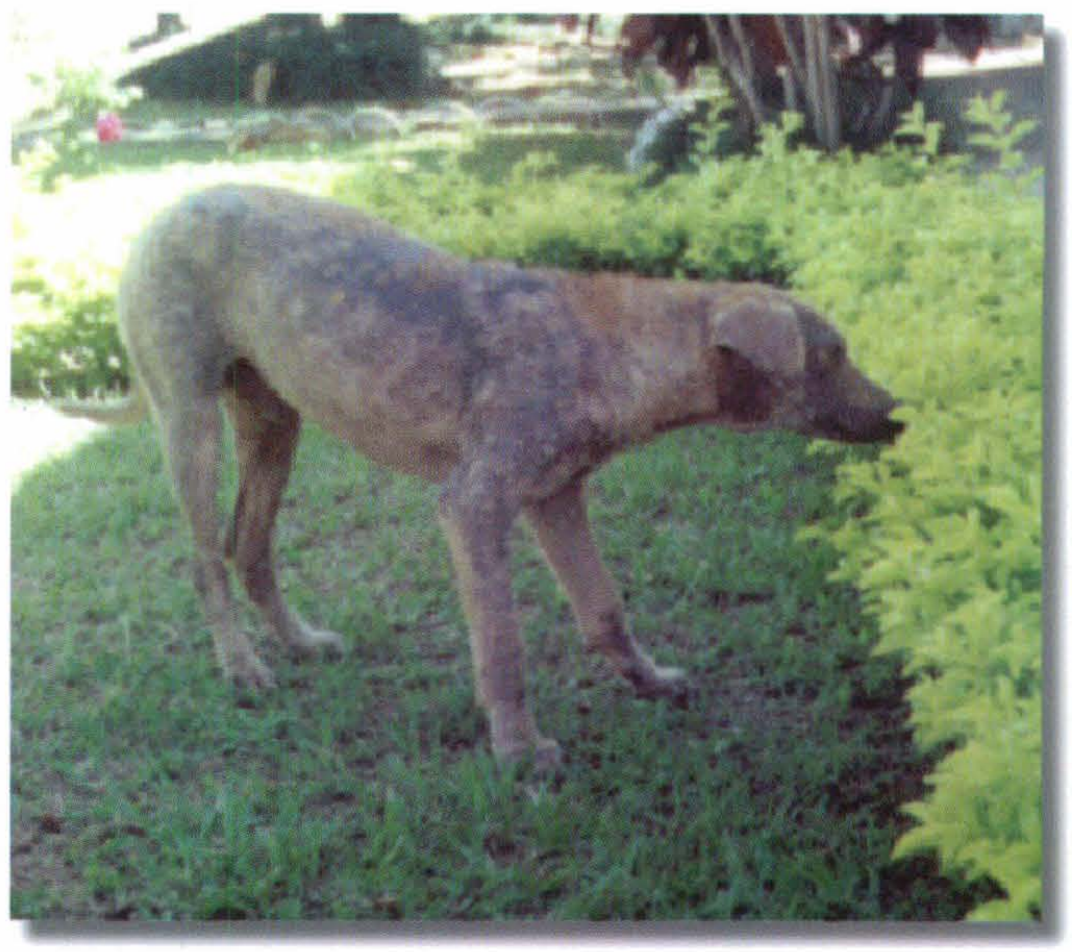

Figura 1: Animal apresentando Sarna Demodécica, sendo tratado com banhos de amitraz,

Um agente acaricida que age pela inibição da monoaminoxidase, o amitraz tem como principal indicação para a sarna demodécica. A medicação é instável e oxida-se rapidamente quando exposta ao ar ou à luz solar. Desta forma é importante não usar o produto vencido ou dividir o conteúdo de um frasco para uso em dias diferentes. O produto oxidado pode apresentar toxicidade aumentada (SCOTT et al., 1996; PENA; ASCHER, 1999).

$\mathrm{O}$ amitraz provoca um efeito sedativo transitório por 12 a 24 horas, especialmente após o primeiro tratamento, e alguns cães tornam-se pruriginosos após as primeiras aplicações (BOOTH, 1992; SCOTT, et al, 1996). A sonolência transitória ou sedação do SNC é mais comum em raças pequenas como Chihuahuas, Yorkshires Terries e Poodles (BOOTH, 1992). Outros efeitos colaterais são raros e incluem reações alérgicas (urticária e edema), irritação cutânea e uma variedade de sinais sistêmicos (SCOTT et al., 1996; ACKERMAN, 1998; GFELLER; MESSONIER, 1998). A ocorrência ou gravidade dos efeitos colaterais diminui com as aplicações subseqüentes. A exposição ao amitraz pode causar dermatite de contato, dores de cabeça ou ataques asmatiformes em algumas pessoas (SCOTT et al., 1996). A segurança do amitraz não foi determinada em cães abaixo dos 4 meses de idade; conseqüentemente, ele é contra-indicado em cães muito jovens (BOOTH, 1992).

O tratamento recomendado consiste em aplicação tópica de amitraz ativo na concentração de $0,025 \%$, totalizando 3 a 6 aplicações (com intervalos de 14 dias) para a demodicose generalizada no cão (Figura 1) (BOOTH, 1992; ACKERMAN, 1998).

Embora o uso de amitraz não esteja aprovado pela FDA no tratamento da escabiose (Figura 2), ele foi utilizado para este objetivo no cão, na mesma concentração $(0,025 \%)$ recomendada para o tratamento da sarna demodécica, com o intervalo de 2 semanas, num total de três aplicações (BOOTH, 1992; ACKERMAN, 1998).

\section{- Milbemicina oxima}

A milbemicina é derivada de produtos de fermentação do fungo Streptomyces higroscopicus, possuindo atividade semelhante à ivermectina, com a notável adição de eficiência na demodicose canina generalizada resistente ao amitraz (MUNDEL, 1998). Os melhores resultados foram obtidos com doses entre 1 a $2 \mathrm{mg} / \mathrm{kg}$, a cada 24 horas, durante 90 dias (MILLER et al., 1993; SCOTT et al., 1996; ACKERMAN, 1998; NESBITT, 1998; CIBA, 1998; PERREIRA; DONAONE,1999).

Semelhante ao caso da ivermectina, alguns Collies são sensíveis à milbemicina em dosagem de $5 \mathrm{mg} / \mathrm{kg}$ ou maiores. Tendo em vista que as dosagens de $1 \mathrm{a}$ 


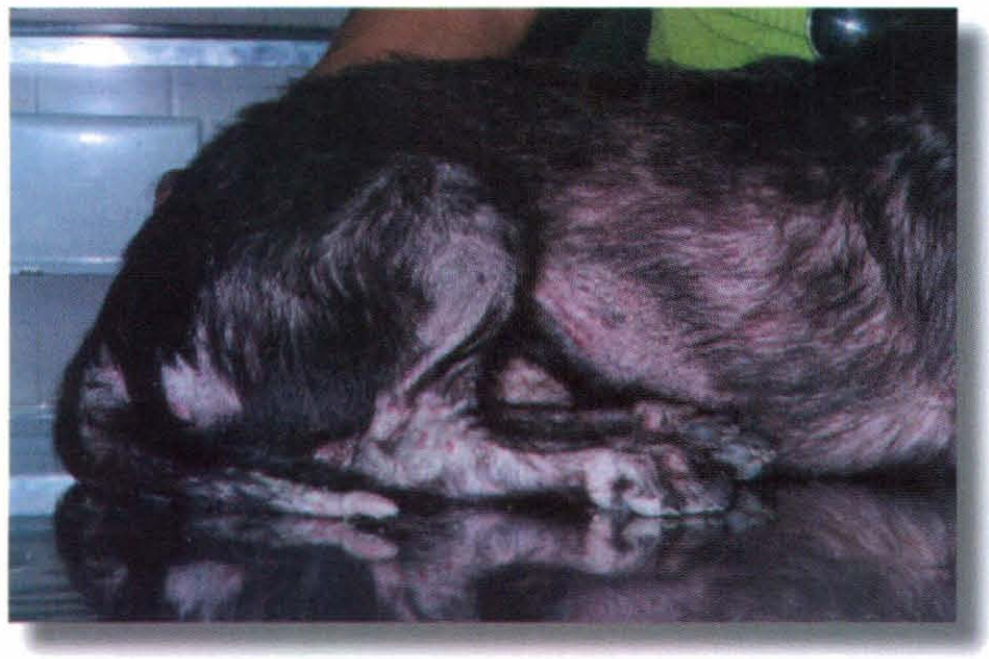

Figura 2: Animal apresentando Sarna Sarcóptica, caracterizada por áreas de eritematosas e alopécicas, caspas e escoriaçōes.

$2 \mathrm{mg} / \mathrm{kg}$ não foram relatadas como causadoras de reações adversas, a milbemicina provavelmenteé segura para uso em Collies com demodicose generalizada, contudo o seu uso não é indicado (SCOTT et al., 1996; NESBITT; ACKERMAN, 1998). Ela só deve ser administrada em cães com idade superior a 12 semanas de vida (ACKERMAN, 1998).

Trabalhos realizados demonstram que a milbemicina é eficaz no controle da sarna sarcóptica quando administrada na dose de $2 \mathrm{mg} / \mathrm{kg}$ a cada sete dias, totalizando três aplicações (MILLER et al., 1996; SCOTT et al., 1996; BERGVALL, 1998).

\section{- Fipronil}

O fipronil é um composto que atua como acaricida e inseticida. Ele age por meio da inibição do fluxo de íons de cloro mediado pelo ácido gama-aminobutírico nas células nervosas periféricas dos artrópodes, provocando paralisia muscular e morte do artrópode. Sua absorção dá-se pela pele, sendo liberado para os folículos pilosos e glândulas sebáceas (ACKERMAN, 1998). Tem tido um alto grau de satisfação com indicação para filhotes a partir de oito semanas de idade e em cadelas gestantes e lactantes (ACKERMAN, 1998; NESBITT, ; ACKERMAN, 1998). A luz solar, imersão em água e banhos não interferem na performance do produto. À base de álcool, o fipronil pode ser irritante para a pele e relativamente caro para cães de raça grande. Cães com longos pêlos podem ter efeito reduzido (ACKERMAN, 1998). Sua formulação está disponível em spot-on (10\% de fipronil) e spray ( $0,25 \%$ de fipronil) (NESBITT; ACKERMAN, 1998; POLLMEIER et al., 2000).

O fipronil é um adulticida com indicação principal contra pulgas, mas também tem sido usado para tratamento de sarna sarcóptica, especialmente em filhotes, fazendo-se 3 a 6 aplicações com fipronil spray $(6 \mathrm{ml} / \mathrm{kg})$, comintervalo de uma semana em cães, inclusive da raça Collie (CURTIS, 1997; ACKERMAN, 1998; ANDRADE et al., 2000).

Nos Quadros 1 e 2 podemos observar de forma resumida as doses dos antiparasitários indicadas pelos autores.

\section{ANTIFÚNGICOS}

\section{Azoles}

Este grupo é subdividido em imidazoles (cetoconazol, clotrimazol, tiabendazol, miconazol e enilconazol) e triazoles (itraconazol e fluconazol). Os azoles são estruturas com amplo espectro antifúngico, compostos por similares mecanismos de ação. Eles se diferenciam em sua farmacocinética, toxidez e uso clínico (JAHAM, 2000). Quanto ao mecanismo de ação, agem inibindo a síntese de ergosterol, o principal lipídeo da membrana das células fúngicas (SCOTT, 1996; NESBITT; ACKERMAN, 1998; JAHAM, 2000). Com o nível de ergosterol diminuído, a célula é incapaz de manter a integridade da membrana, e o resultado é a permeabilidade aumentada, degeneração celular e morte (HILL et al., 1995).

\begin{tabular}{|c|c|c|}
\hline DROGAS & NOME COMERCIAL & DOSE'/ VIA / FREQÜÊNCIA \\
\hline Ivermectina & Ivomec $($ & $\begin{array}{l}0,2-0,4 \mathrm{mg} / \mathrm{kg} / \mathrm{VO}, \mathrm{SC} / \\
\text { a cada } 2 \mathrm{sem} / 2-3 \text { ap }\end{array}$ \\
\hline Selamectina & Revolution $\circledast$ & $\begin{array}{l}6 \mathrm{mg} / \mathrm{kg} / \mathrm{TO} / \mathrm{a} \text { cada } 30 \mathrm{~d} / \\
1 \text { a } 2 \text { ap }\end{array}$ \\
\hline Amitraz & Triatox® & $\begin{array}{l}\text { Banhos na concentração de } \\
0,025 \% \text { / a cada } 2 \text { sem / } 3 \text { ap }\end{array}$ \\
\hline $\begin{array}{l}\text { Milbemicina } \\
\text { oxima }\end{array}$ & Interceptor ${ }^{\circledR}$ & $2 \mathrm{mg} / \mathrm{kg} / \mathrm{a}$ cada $7 \mathrm{~d} / 3$ ap \\
\hline Fipronil spray & Frontline $®$ & $\begin{array}{l}6 \mathrm{~mL} / \mathrm{kg} / \mathrm{TO} / \mathrm{a} \text { cada } 7 \mathrm{~d} / \\
3 \text { a } 6 \mathrm{ap}\end{array}$ \\
\hline \multicolumn{3}{|c|}{$\begin{array}{l}\text { Legenda: VO: via oral / SC: via subcutânea / TO: via tópica / d: dias / ap: aplicações / } \\
\text { sem: semanas }\end{array}$} \\
\hline
\end{tabular}

Quadro 1: Protocolo para uso de antiparasitários na escabiose canina, segundo literatura revisada. 


\begin{tabular}{|c|c|c|}
\hline DROGAS & NOME COMERCIAL & DOSE / VIA / FREQÜÊNCIA \\
\hline Ivermectina & Ivomec ( & 0,3-0,6 mg/kg / VO / SID \\
\hline Moxidectina & Cydectin $®$ & $0,4 \mathrm{mg} / \mathrm{kg} / \mathrm{VO} / \mathrm{SID} / 5 \mathrm{~m}$ ou \\
\hline Amitraz & Triatox® & $\begin{array}{l}0,5-1 \mathrm{mg} / \mathrm{kg} / \mathrm{VO}, \mathrm{SC} / 2 \times \mathrm{sem} \\
/ 22 \mathrm{sem}\end{array}$ \\
\hline $\begin{array}{l}\text { Milbemicina } \\
\text { oxima }\end{array}$ & Interceptor ( & $\begin{array}{l}\text { Banhos na concentração de } \\
0,025 \% \text { / a cada } 2 \text { sem / } 3 \text { a } \\
6 \text { ap } 1-2 \text { mg/kg / VO / SID / } 3 \mathrm{~m}\end{array}$ \\
\hline $\begin{array}{l}\text { Legenda: VO: vi } \\
\text { d: dias / ap: apli }\end{array}$ & $\begin{array}{l}\text { / } \mathrm{SC} \text { : via subcutânea / TO } \\
\text { / sem: semana }(\mathrm{s}) / \mathrm{m} \text { : me: }\end{array}$ & $\begin{array}{l}\text { via tópica / SID: uma vez ao dia / } \\
\text { s }\end{array}$ \\
\hline
\end{tabular}

Quadro 2. Protocolo para uso de antiparasitários na demodicose canina, segundo literatura revisada

\section{- Cetoconazol}

O cetoconazol, derivado imidazólico fúngico, possui atividade contra muitos fungos e leveduras, inclusive dermatófitos, cândidas, malassézias, e inúmeros fungos responsáveis por micoses sistêmicas. O efeito do cetoconazol é retardado; o estabelecimento de ação demora de 5 a 10 dias (SCOTT et al., 1996). Possui distribuição na superfície da pele e no pêlo, prevenindo a invasão fúngica (MEDLEAU, 1994).

O cetoconazol é insolúvel em água, mas solúvel em soluções ácidas diluídas, e a acidez gástrica aumentada promove a absorção. Quando é administrado com alimentos, a absorção é aumentada (HILL et al., 1995; SCOTT et al., 1996; NESBITT; ACKERMAN, 1998; JAHAM, 2000; NOLI, 2000). Não deve ser administrado com antiácidos gástricos, como os agentes cimetidina e anticolinérgicos (SCOTT et al., 1996; NESBITT; ACKERMAN, 1998).

Muitos relatos indicam a dosagem e freqüência de administração, sugerindo $10 \mathrm{mg} / \mathrm{kg}$, a cada 12 ou 24 horas, por via oral. Nas micoses sistêmicas, dosagens mais elevadas ( 30 a 40 mg/kg/dia) comumente são necessárias. Apesar de este agente ser relativamente bem tolerado, ocorrem efeitos colaterais nos cães, incluindo inapetência, prurido e alopecia. Com doses superiores a $40 \mathrm{mg} / \mathrm{kg} / \mathrm{dia}$, houve anorexia, náusea e níveis aumentados de enzimas hepáticas (SCOTT et al., 1996; NESBITT; ACKERMAN, 1998).

Para uso tópico, o cetonazol xampu possui indicação a cada 3 dias na concentração de $2 \%$, auxiliando o tratamento sistêmico (FINCH; SNYDER, 1994; SCOTT et al., 1996; BEALE, 1998).

\section{- Itraconazol}

O itraconazol é um triazol semelhante aos derivados imidazólicos. Os microrganismos susceptíveis incluem os dermatófitos, cândidas, malassézias e aqueles que causam micoses profundas. Tem sido usado no tratamento de micoses sistêmicas na dose de 10 a $20 \mathrm{mg} / \mathrm{kg}$ a cada 24 ou 48 horas, por via oral. (SCOTT, 1996). Nas dermatofitoses está indicado na dose de 5 a $10 \mathrm{mg} / \mathrm{kg}$, a cada 24 horas (NESBITT, 1998; MORIELLO, 1995; JAHAM, 2000). É mais eficiente que o cetoconazol. Estudos sobre a toxicidade em cães demonstraram que, mesmo na dose de $40 \mathrm{mg} / \mathrm{kg}$, uma vez ao dia, durante 90 dias, não apresentou reações adversas (SCOTT, 1996). Não possui recomendação durante a prenhez, em virtude dos efeitos teratogênicos com altas dosagens; tais efeitos não foram detectados na dose de $10 \mathrm{mg} / \mathrm{kg} / \mathrm{dia}$ (SCOTT, 1996; MORIELLO, 1995). Estudos demonstram que sua absorção é maior quando administrada com as refeições. Sua máxima absorção ocorre com um aumento da acidez gástrica (HILL, 1995). É metabolizado pelo fígado e excretado pela urina e fezes (JAHAM, 2000). Seu metabólito, hidróxido-itraconazol, retém atividade antifúngica (FINCH, 1994).

\section{Alilaminas}

A alilamina é um derivado de uma nova classe de antifúngicos sintéticos, da qual a terbinafina e naftidini fazem parte. Possui ação fungicida (JAHAM, 2000).

\section{- Terbinafina}

Assim como os azoles, as alilaminas são potentes inibidores do ergosterol sintético (JAHAM, 2000). $\mathrm{O}$ mecanismo de ação dá-se pela deficiência de ergosterol, que é o principal esteróide da membrana fúngica (HILL, 1995). Ao contrário dos azoles, a terbinafina pode não afetar os níveis de cortisol ou testosterona, até mesmo em altas doses (JAHAM, 2000). Clinicamente tem-se mostrado excelente eficácia contra dermatófitos, contudo, parece ser ineficiente para o tratamento de micoses profundas (REES, 1999; JAHAM, 2000). A dose utilizada para cães é de 10 a $13 \mathrm{mg} / \mathrm{kg}$ diariamente, por via oral (REES, 1999). Embora a biodisponibilidade seja maior quando fornecida com alimentos com alto teor de lipídeos, também é bem absorvida na ausência deles. Após a absorção, a maior parte da droga é 
metabolizada no fígado, devendo a dosagem ser regulada em pacientes com disfunções hepáticas (JAHAM, 2000).

\section{Outras Drogas Utilizadas}

\section{- Clorexidina}

A clorexidina é um anti-séptico biguanida relacionado ao fenol com excelentes propriedades. Possui eficiência contra muitos fungos, vírus e a maior parte das bactérias. Não é irritante, raramente é sensibilizante e não é inativada por matéria orgânica. Possui ação persistente; é eficiente em formulações de xampu, contendo 0,5 a $3 \%$ de concentrações de diacetato ou gliconato de clorexidina (GUAGUERE, 1996; SCOTT et al., 1996). Para o uso em dermatoses por Malassezia são recomendadas as concentrações entre 2 a $4 \%$. (MORIELLO;

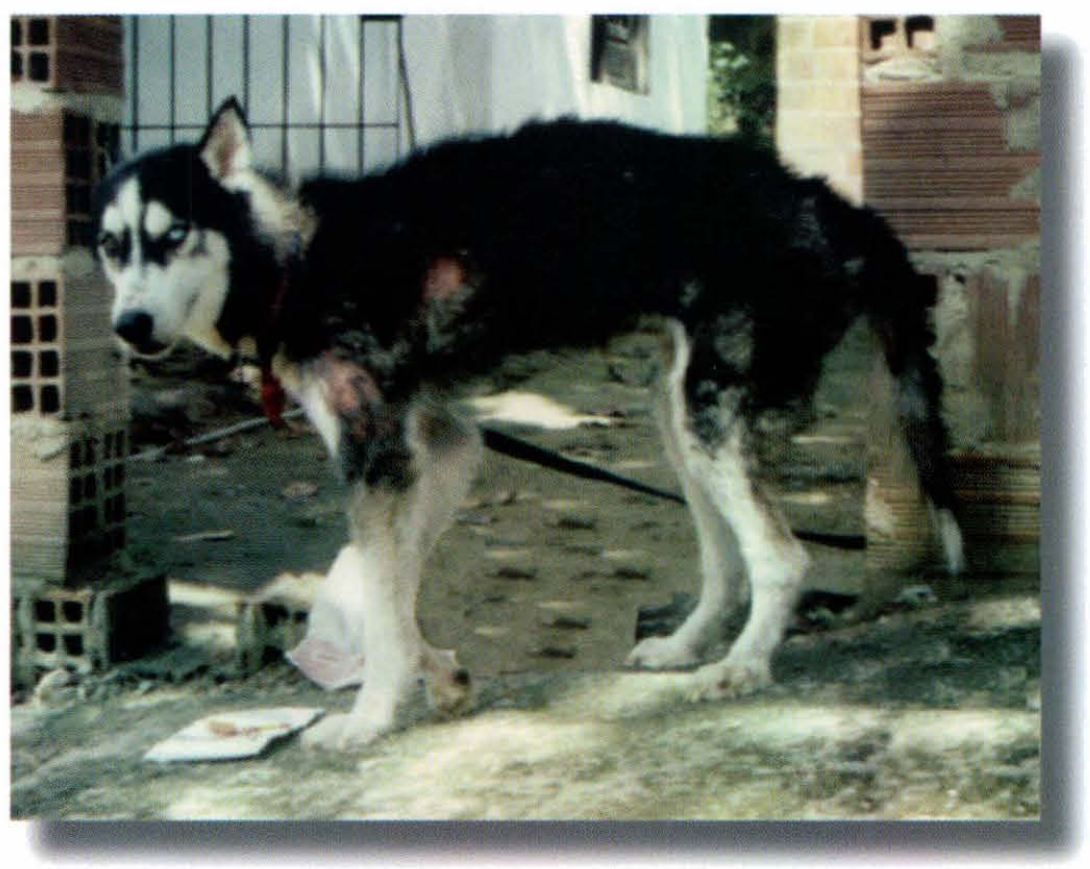

Figura 3: Animal apresentando Dermatite Bacteriana com alterações de áreas alopécicas e erosões.
MANSON, 1995; NESBITT; ACKERMAN, 1998). É indicado banhos a cada 3 ou 5 dias, auxiliando o tratamento sistêmico (BEALE, 1998).

\section{- Lufenuron}

O lufenuron é um inseticida que inibe a síntese de quitina, que é o principal componente do exoesqueleto da pulga (SCOTT et al., 1996; NESBITT; ACKERMAN, 1998). A droga é depositada no tecido adiposo subcutâneo e é liberada lentamente para o sangue (PARADIS, 1999).

Trabalhos recentes demonstram que o lufenuron além de controlar pulgas também trata e previne dermatófitos na dosagem de $60 \mathrm{mg} /$ $\mathrm{kg}$ em dose única (ZIONY, 2000; PROGRAM, 2001).

A s doses e a frequiência dos antifúngicos encontram-se na Quadro 3.

\section{ANTIBIÓtICOS}

\section{Beta-lactâmicos}

Todos os medicamentos pertencentes a esta classe têm em comum o anel betalactâmico, que é essencial para atividade antibacteriana. Visto que os antibióticos beta-lactâmicos atuam na parede celular, e visto que nossos pacientes não possuem tal parede, este grupo de medicamentos é extremamente seguro. Dentre eles temos as cefalosporinas, penicilinas e carbacefemos
(HUBER, 1992; LLOYD, 1994; SNYDER; FINCH, 1994; PAPICH, 1997).

As cefalosporinas são antibióticos bactericidas que atuam contra bactérias gram-positivas e várias gramnegativas, sendo utilizadas no tratamento de pele e outras afecções sistêmicas. A primeira geração de cefalosporinas (cefadroxil, cefalexina, cefradine, cefalotin, cefazolin e cefapirin) é ativa contra bactérias gram-positivas e outras bactérias gram-negativas, como Escherichia coli, Proteus e Klebsiella spp. A segunda, terceira e quarta gerações são indicadas mais para

\begin{tabular}{|c|c|c|}
\hline DROGAS & NOME COMERCIAL & DOSE / VIA / FREQÜÊNCIA \\
\hline Cetoconazol & $\begin{array}{l}\text { Cetoconazol } 8 \\
\text { Nizoral } ₫\end{array}$ & $\begin{array}{l}10 \mathrm{mg} / \mathrm{kg} / \mathrm{VO} / \mathrm{SID}, \mathrm{BID} \\
\text { Banhos a cada } 3 \mathrm{~d}\end{array}$ \\
\hline Itraconazol & Traconal@ & $5-10 \mathrm{mg} / \mathrm{kg} / \mathrm{VO} / \mathrm{SID}$ \\
\hline Terbinafina & Terbizol® & $10-13 \mathrm{mg} / \mathrm{kg} / \mathrm{VO} / \mathrm{SID}$ \\
\hline Clorexidina & $\begin{array}{l}\text { Vetriderm } \\
\text { Clorexidine }{ }^{8}\end{array}$ & Banhos a cada 3 a $5 d$ \\
\hline Lufenuron & Program $®$ & $60 \mathrm{mg} / \mathrm{kg} / \mathrm{DU}$ \\
\hline
\end{tabular}

Quadro 3. Protocolo para uso de antifúngicos na dermatofitose canina, segundo literatura revisada. 
microrganismos gram-negativos e anaeróbios, embora possuam também atividade contra gram-positivos. São potencialmente nefrotóxicas e possui eliminação por via renal (ALLEN et al., 1998).

\section{- Cefalexina}

A cefalexina é o antibiótico bactericida mais usado em antibioticoterapias por tempo prolongado. Possui uma boa atividade contra o estafilococos, Proteus e algumas pseudomonas (WHITE, 1996; FISCHER et al., 2000).

A dose indicada é de $22-33 \mathrm{mg} / \mathrm{kg}$, oralmente, a cada 8 ou 12 horas (NESBITT; ACKERMAN, 1998; ROSSER JR., 1998; GUAGUERE et al.,1998; WILKINSON, 1999; ROOSGE, 2000). Os efeitos colaterais observados foram salivação, taquipnéia e excitabilidade (ALLEN et al., 1998).

\section{- Cefpodoxima}

É um antibiótico beta-lactâmico, sendo reservado para doenças de pele crônicas, que são refratárias à medicação tradicional. Esta droga é relativamente resistente à beta-lactamase do estafilococos. Ela é uma cefalosporina de terceira geração e pode ser administrada oralmente na dose de 5 a $10 \mathrm{mg} / \mathrm{kg}$, a cada 6 ou 8 horas, para cães. Os efeitos colaterais incluem vômito e diarréia (REES, 1999).

\section{Fluoroquinolonas}

As fluoroquinolonas possuem mecanismo de ação único. Estes agentes inibem a enzima DNA-girase, provocando redução na transcrição e translação do código genético, inibindo, assim, a síntese das proteínas. As enzimas dos mamíferos são resistentes às concentrações antibacterianas comumente alcançadas. A eliminação ocorre basicamente pelos rins (PAPICH, 1997).

Os efeitos colaterais das fluoroquinolonas são defeitos na cartilagem articular em animais em crescimento. Essas drogas não devem ser usadas em animais mais jovens do que um ano, e em raças grandes o uso deve ser evitado com idade inferior a 18 meses de vida. Adicionais efeitos, mas não comuns, estão a cristalúria, glicosúria, estimulação do SNC e inapetência observadas apenas quando administrada em alta dose (20 mg/ $\mathrm{kg}$ oral a cada 24 horas) (REES, 1999).

\section{- Enrofloxacina}

A enrofloxacina possui uma boa eficácia no tratamento de piodermites superficiais (Figura 3 ) e profundas em razão de sua atividade contra Staphylococcus intermedius (ALLEN et al., 1998; FEVE et al., 1998; GUAGUERE et al., 1998). A dose recomendada pode variar entre 2,5 a $5 \mathrm{mg} / \mathrm{kg}$, podendo ser a cada 12 ou 24 horas, por via oral, sendo a dose mais alta indicada para dermatites profundas ou outros processos infecciosos (WHITE, 1996; REES, 1999).

\section{- Difloxacina}

É uma fluoroquinolona efetiva no tratamento contra gram-negativas e gram-positivas bactérias associadas em dermatites de cães. Possui boa penetração na pele. A dose recomendada é 5 a $10 \mathrm{mg} / \mathrm{kg}$ a cada 24 horas, por via oral (REES, 1999).

\section{Macrolídeos}

Este grupo de antibióticos liga-se à subunidade 50$\mathrm{S}$ dos ribossomos e interfere com a translocação necessária para o crescimento da cadeia peptídica. São eficientes contra as bactérias gram-negativas, exceto algumas linhagens da Pasteurella. Também é susceptível às bactérias estafilococos e estreptococos. Todos os medicamentos deste grupo são metabolizados pelo fígado (PAPICH, 1997; ALLEN et al., 1998).

\section{- Azitromicina}

A dose recomendada é de 5 a $10 \mathrm{mg} / \mathrm{kg}$, por via oral, a cada 24 horas. Deve ser administrada uma hora antes ou duas horas após a refeição, para que não haja interferência na sua absorção (WHITE, 1996; REES, 1999).

\section{- Tilosina}

Possui indicação entre 10 a $20 \mathrm{mg} / \mathrm{kg}$ administradas oralmente a cada 12 horas (REES, 1999; ROOSGE, 2000). Não é aprovado o seu uso em cães e gatos, mas tem excelente atividade contra o Staphylococcus intermedius na dose de $20 \mathrm{mg} / \mathrm{kg}$, a cada 12 horas (WHITE, 1996). Os defeitos adversos relatados foram anorexia e diarréia (ALLEN et al., 1998).

\section{Outras Drogas Utilizadas}

\section{- Peróxido de benzoíla}

É encontrado como xampu nas concentrações de 2,5 a 3\%. Além de ter ação antifúngica, ceratolítica e realizar lavagem folicular, possui ação antibacteriana, sendo indicado banhos a cada três dias (NESBITT; ACKERMAN, 1998; PARADIS, 1999).

Seu mecanismo de ação é bem conhecido. É um agente oxidante, que produz uma série de reações químicas na pele, resultando em alteração na permeabilidade ou ruptura da membrana bacteriana (GUAGUERE, 1996). Por ser um produto instável, 


\begin{tabular}{|c|c|c|}
\hline DROGAS & NOME COMERCIAL & DOSE / VIA / FREQÜÊNCIA \\
\hline Cefalexina & Rilexine ${ }^{8}$ & $22-33 \mathrm{mg} / \mathrm{kg} / \mathrm{VO} / \mathrm{BID}$, TID \\
\hline Cefpodoxima & Vantin® & $5-10 \mathrm{mg} / \mathrm{kg} / \mathrm{VO} / \mathrm{TID}$, QID \\
\hline Terbinafina & Baytrilß & $2,5-5 \mathrm{mg} / \mathrm{kg} / \mathrm{VO} / \mathrm{SID}, \mathrm{BID}$ \\
\hline Difloxacina & Dicural@ & $5-10 \mathrm{mg} / \mathrm{kg} / \mathrm{VO} / \mathrm{SID}$ \\
\hline Azitromicina & Zitromax® & $5-10 \mathrm{mg} / \mathrm{kg} / \mathrm{VO} / \mathrm{SID}$ \\
\hline Tilosina & Tilacare $®$ & $10-20 \mathrm{mg} / \mathrm{kg} / \mathrm{VO} / \mathrm{SID}$ \\
\hline $\begin{array}{l}\text { Peróxiodo de } \\
\text { Benzoila }\end{array}$ & Peroxidex® & Banhos a cada $3 d$ \\
\hline Clorexidina & $\begin{array}{l}\text { Vetriderm } \\
\text { Clorexidine }{ }^{2}\end{array}$ & Banhos a cada 3 ou $5 d$ \\
\hline \multicolumn{3}{|c|}{$\begin{array}{l}\text { Legenda: VO: via oral / SID: uma vez ao dia / BID: duas vezes ao dia / TID: três vezes } \\
\text { ao dia / QID: quatro vezes ao dia / d: dias }\end{array}$} \\
\hline
\end{tabular}

Quadro 4: Protocolo para uso de antibióticos na dermatites bacterianas em cães, segundo literatura revisada.

não deve ser reembalado, diluído ou misturado a outros produtos. Ele resseca excessivamente a pele normal com o seu uso prolongado, por sua ação desengordurante poderosa, sendo contra-indicado na pele seca. Esse efeito pode ser minimizado se associado a um umectante. Pode causar descoramento da pele e da roupagem (MASON, 1993; SCOTT et al., 1996; NESBITT; ACKERMAN, 1998).

\section{- Clorexidina}

Como já foi citada, a clorexidina possui atividade antifúngica e antibacteriana para a maioria das bactérias, exceto, talvez, algumas cepas de Pseudomona e Serratia (SCOTT, 1996). Para o uso em dermatites bacterianas é recomendado banhos a cada 3 ou 5 dias, nas concentrações entre 2,5 a $3 \%$, como mostra a Quadro 4 (MORIELLO; MANSON, 1995; NESBITT; ACKERMAN, 1998).

\section{Conclusão}

Um conhecimento mais profundo das diversas drogas administradas em dermatopatias caninas, traz ao clínico uma maior segurança à sua utilização acompanhada de uma boa resposta terapêutica. Com a variedade de agentes causadores de alterações dermatológicas, a indicação correta do fármaco é essencial, a fim de evitar efeitos colaterais.

\section{SUMMARY}

Besides having a correct diagnosis, efficient drugs with few side effects need to be used in dermatological disorders of dogs. As a result, this review updates the information available on the drugs presently used in the parasitic, fungal and bacterial dermatosis most commonly found in veterinary practice.

Key word: Dog. Dermatosis. Antiparasite. Antifungal. Antibacterial. Skin.

\section{RESUMEN}

Las alteraciones dermatológicas en perros necesitan, además de un diagnóstico correcto, el uso de drogas que posean eficacia y produzcan pocos efectos colaterales. Por lo tanto, en esta revisión, presentaremos informaciones sobre las drogas que se están utilizando en dermatosis parasitarias, fúngicas y bacterianas más comunes en la actividad diaria de la clínica veterinaria.

Palabras clave: Perro. Dermatosis. Antimicótico. Antibacteriano. Antiparasitario. Piel. 


\section{REFERÊENIAS}

ACKERMAN, L. J. Canine parasitic diseases. In: NESBITT, G. H.; ACKERMAN, L. J. Canine \& feline dermatology. New Jersey: Veterinary Learning Systems, 1998. cap. 6, p. 162-198.

ALLEN, D. G.; PRINGLE, J. K.; SMITH, D. A. Description of drugs for small animals. In:__ Veterinary drugs. 2 th ed. Philadelphia: Lippincott Williams \& Wilkins, 1998. cap. 3, p. 63 339.

ANDERSON, R. K. Sarna sarcóptica, sarna notoédrica e queiletielose. In: BIRCHARD, S. J.; SHERDING, R. G. Clínica de pequenos animais. São Paulo: Roca, 1998. cap. 5, p. 335-338.

ANDRADE, S. F. et al. Uso de fipronil spray no tratamento da escabiose canina. Revista Brasileira de Ciência Veterinária, Niterói, v. 7, n. 1, p. 101, sep. 2000. Suplemento.

BEALE, K. M. Dermatofitose. In: BIRCHARD, S. J.; SHERDING, R. G. Clínica de pequenos animais. São Paulo: Roca, 1998. cap. 3, p. 321-328.

BENSIGNOR, E.; CARLOTTI, D. N. Moxidectine in the treatment of generalized demodicosis in dogs: a pilot study: 8 cases. In: KWOCHKA, K. W. Advances in veterinary dermatology. Edinburgh: Butterworth Heinemann, 1998. v.3, cap. 9, p. 554 555 .

BERGVALL, K. Clinical efficacy of milbemycin oxime in the treatment of canine scabies: a study of 56 cases. Veterinary Dermatology, Lisboa, v. 9, n. 4, p. 231-233, Dec. 1998.

BOOTH, N. H. Drogas de ação local na pele, nas mucosas, olhos e ouvidos. In: BOOTH, N. H.; MCDONALD, L.E. Farmacologia e terapêutica em veterinária. 6. ed. Rio de Janeiro: Guanabara Koogan, 1992. cap. 44, p. 581-599.

CHESNEY, C. J. Short form of Demodex species mite in the dog: occurrence and measurements. Journal of Small Animal Practice, London, v. 40, n. 2, p. 58-61, Feb. 1999.

CIBA Saúde Animal. Interceptor. Manual Técnico, São Paulo, [1998], 19 p.

CURTIS, C. F. Uso de fipronil spray $0,25 \% *$ no tratamento de sarna sarcóptica em uma ninhada de filhotes de cinco semanas de idade. A Hora Veterinária, Porto Alegre, v. 17, n. 98, p. 4547, jul./ago. 1997.
DELAYTE, E. H. et al. Terapia da demodicidose com moxidectina - efeitos colaterais e eficácia. In: CONGRESSO PAULISTA DE CLÍNICOS VETERINÁRIOS DEPEQUENOS ANIMAIS, 1., 2001, Águas de Lindóia. Resumo dos trabalhos. p. 19.

FEVE, C.; DELLAC, B.; LIMET, A. Use of enrofloxacin in the treatment of canine pyoderma. Advances in veterinary dermatology. Edinburgh: Butterworth Heinemann, 1998. v.3, cap. 9, p. 543.

FINCH, R. G.; SNYDER, I. S. Drogas antifúngicas. In: CRAIG, C. R.; STITZEL, R. E. Farmacologia moderna. 4. ed. Rio de Janeiro: Guanabara Koogan, 1994. cap. 59, p. 579-587.

FISCHER, O. et al. Comparison of cephalexin and enrofloxacin in the treatment of bacterial folliculits in dogs. Revista Brasileira de Ciência Veterinária, Niterói, v. 7, n.1, p. 86, sep. 2000. Suplemento.

FONDATI, A. Efficacy of daily oral ivermectin in the treatment of 10 cases of generalized demodicoses in adult dogs. Veterinary Dermatology, Lisboa, v. 7, n. 2, p. 99-114, Jun. 1996.

GFELLER, R. W.; MESSONIER, S. P. Toxic drugs and chemicals. In: 1998. cap. 2, p.65-268. Small animal toxicology. Missouri: Mosby,

GRAY, A. K. Avermectin toxicity in the dog. The Veterinary Record, London, v. 140, n. 21, p. 563, May 1997.

GUAGUERE, E. Topical treatment of canine and feline pyoderma. Veterinary Dermatology, Lisboa, v. 7, n. 3, p. 145-151, Sep. 1996.

GUAGUERE, E.; MAYNARD, L.; SALOMON, C. Cephalexin in the treatment of canine pyoderma: comparison of two dose rates. In: KWOCHKA, K. W. Advances in veterinary dermatology. Edinburgh: Butterworth Heinemann, 1998. v. 3, cap. 9, p. $554-555$.

HILL, P. B.; MORIELLO, K.A.; SHAW, S.E. A review of systemic antifungal agents. Veterinary Dermatology, Lisboa, v. 6, n. 2, p. 59-66, 1995.

HUBER, W. G. Penicilinas. In: BOOTH, N. H.; MCDONALD, L.E. Farmacologia e terapêutica em veterinária. 6. ed. Rio de Janeiro: Guanabara Koogan, 1992. cap. 49, p. 642654. 
JAHAM, C. Antifungal dermatologic agents: azoles and allylamines. The Compendium on Continuing Education for the Practicing Veterinarian, Princeton, v. 22, n. 6, p. 548-559, jun. 2000.

LLOYD, D. H. Tratamiento de la pioderma canina. In: BONAGURA, K. Terapéutica veterinária de pequenos animales. 11. ed. Madrid: Interamericana, 1994 cap. 7, p. 596-601.

LUCAS, R. et al. Efeitos colaterais observados em cães com demodicose tratados pela moxedectina. In: CONGRESSO PAULISTA DE CLÍNICOS VETERINÁRIOS DE PEQUENOS ANIMAIS, 1., 2000, Águas de Lindóia. Resumodos trabalhos. p. 19.

MASON, I. S. Antibacterial strategies. In: LOCKE, P. H.; HARVEY, R. G.; MASON, I. S. Manual of small animal dermatology. Gloucestershire: Looker, 1993. cap. 25, p. 213-219.

MATTHEW, W. B. et al. Respiratory failure attributable to moxidectin intoxication in a dog. Journal of the American Veterinary Medical Association, Schaumburg, v. 215, n. 12, p. 1813-1817, Dec. 1999.

MEDLEAU, L. Dermatofitose felina. In: BONAGURA, K. Terapéutica veterinária de pequenos animales. 11. ed. Madrid: Interamericana, 1994. cap. 7, p. 617-619.

MEDLEAU, L.; RISTIC,Z.; MCELVEEN, D. R. Daily ivermectin for treatment of generalized demodicosis in dogs. Veterinary Dermatology, Lisboa, v. 7, n. 4, p. 209-212, Dec. 1996.

MILLER, W. H. et al. Clinical efficacy of increased dosages of milbemycin oxime for treatment of generalized demodicoses in adult dogs. Journal of the American Veterinary Medical Association, Schaumburg, v. 203, n. 10, p. 1426-1429, Nov. 1993.

MILLER, W. H. et al. Treatment of canine scabies with milbemycin oxime. Canadian Veterinary Journal, Ottawa, v. 37, n. 4, p. 219-221, Apr. 1996.

MORIELLO, K. A. Tratamiento de las infestaciones por sarcoptes y cheyletiella. In: BONAGURA, K. Terapéutica veterinária de pequenos animales. 11. ed. Madrid: Interamericana, 1994. cap. 7, p. 617-619.

MORIELLO, K.; MASON, I. Control of ectoparasites. In: MASON, I.; MORIELLO, K. Small animal dermatology. Trowbridge: Pergamon, 1995. cap. 30, p. 275-278.

MUNDELL, A. C. Demodicose. In: BIRCHARD, S. J.; SHERDING, R. G. Clínica de pequenos animais. São Paulo: Roca, 1998. cap. 4, p. 329-334.
NESBITT, G. H.; ACKERMAN, L. J. Dermatotherapeutics. In: Canine $\&$ feline dermatology. New Jersey: Veterinary Learning Systems, 1998. cap. 3, p. 71-108.

NOLI, C. Superficial mycoses: problems in diagnosis and therapy. In: WORLD CONGRESS, 1., 2000. Amsterdam. Scientifics Proceedings. Amsterdam: Made With, 2000. 1 CD.

PAPICH, M. G. Medicamentos antimicrobianos. In: ETTINGER, S.J; FELDMAN, E. C. Tratado de medicina interna Veterinária. São Paulo: Manole, 1997. cap 58, p. 389-405. 1v.

PARADIS, M. New approaches to the treatment of canine demodicosis. The Veterinary Clinics of North America: Small Animal Practice, Philadelphia, v. 29, n. 6, p. 1425-1436, Nov. 1999.

PENA, A. E.; ASCHER, F. Comparison of an amitraz-impregnated collar with topical administration of fipronil for prevention of experimental and natural infestations by the Brown dog tick (Rhipicephalus sanguineus). Journal of the American Veterinary Medical Association, Schaumburg, v. 214, n. 2, p. 1799-1803, Jun. 1999.

PERREIRA, E. C. P.; DONHONE, A. Tratamento de demodicose canina com milbemicina oxima. Inovação, São Paulo, v. 1, n. 2, p. 3, [1999].

PRÁTICA Médica. Controle de pulgas, ácaros e carrapatos com REVOLUTION@. Um novo agente tópico de amplo espectro para cães e gatos. Tópicos em Medicina Veterinária, São Paulo, v. 1, n. 2, p. 14-21, 2000.

PROGRAM: o controle de pulgas e de infecções fúngicas em um só tratamento. Inovação, São Paulo, v. 3, n. 7, p. 3-4, [2001].

POLLMIER, M. et al. Eficácia de fipronil contra Sarcoptes scabei, variante canis, em cães. Boletim Técnico, São Paulo, [2000], p. 2.

REES, C. A. New drugs in veterinary dermatology. The Veterinary Clinics of North America: Small Animal Practice, Philadelphia, v. 29, n. 6, p. 1449-1460, Nov. 1999.

ROBERSON, E. L. Drogas usadas contra nematódeos. In: BOOTH, N. H.; MCDONALD, L. E. Farmacologia e terapêutica em veterinária. 6. ed. Rio de Janeiro: Guanabara Koogan, 1992. cap. 55, p. $711-749$.

ROOSGE, P. J. Current concepts of antibiotic therapy in dermatology. In: WORLD CONGRESS, 2000, Amsterdam. Scientifics Proceedings. Amsterdam: Made with, 2000. 1 CD. 
Peixoto A. S.; Coelho M. C. O. C.; Barbosa M. B. - Atualidades em tratamentos utilizados em dermatopatias de cães - Revisão - Treatments for dermatopathies in dogs - A review - Actualidades en tratamientos utilizados en dermatopatías en perros - revisión - Rev. educ. contin. CRMV-SP / Continuous Education Journal CRMV-SP. - São Paulo. volume 5, fascículo 1, p. 14 - 24, 2002

ROSSER JR., E. J. Distúrbios cutâneos e auditivos. In: BIRCHARD, S. J.; SHERDING, R. G. Clínica de pequenos animais. São Paulo: Roca, 1998. cap. 1, p. 309-316.

SARIDOMICHELAKIS, M. et al. Adult-onset demodicoses in two dogs due to Demodex canis and a short-tailed demodectic mite. Journal of Small Animal Practice, London, v. 40, n. 11, p. 529-532, nov. 1999.

SCHICK, M. P.; SCHICK, R. O. Doenças do pavilhão auricular. In: BIRCHARD, S. J.; SHERDING, R. G. Clínica de pequenos animais. São Paulo: Roca, 1998. cap. 20, p. 417-423.

SCOTT, D. W.; MILLER JR., W. H.; GRIFFIN, C. E. Tratamento dermatológico. In: Dermatologia de pequenos animais. 5. ed. Rio de Janeiro: Interlivros, 1996. cap. 3, p. 158255.

SHANKS, D.J. et al. The efficacy of selamectin in the treatment of naturally acquired. Veterinary Parasitology, New York, v. 91, n. 3-4, p. 269-281, Aug. 2000.
SIX, R. H. et al. Efficacy and safety of selamectin against Sarcoptes scabei on dogs and otodectes cynotis on dogs and cats presented as veterinary patients. Veterinary Parasitology, New York, v. 91, n. 3-4, p. 291-309, Aug. 2000.

SNYDER, S. I.; FINCH, R. G. Antibióticos beta-lactâmicos. In: CRAIG, C. R.; STITZEL, R. E. Farmacologia moderna. 4. ed. Rio de Janeiro: Guanabara Koogan, 1994. cap. 49, p. 495-506.

WILKINSON, G. T.; HARVEY, R. G. Bacterial skin diseases. In: Color atlas of small animal dermatology. 2. ed. Barcelona: Mosby, 1999. cap. 5, p. 89-107.

WHITE, S. D. Systemic treatment of bacterial skin infections of dogs and cats. Veterinary Dermatology, Lisboa, v. 7, n. 3, p. 99-104, Sep. 1996.

ZIONY, Y. B. Uso of lufenuron for treating fungal infections of dogs and cats: 297 cases (1997-1999). Journal of the American Veterinary Medical Association, Schaumburg, v. 217, n. 10, p. 1510-1513, Nov. 2000. 